\title{
Psychopathological conditions and somatic consequences of a suicide attempt with a corrosive substance in a patient suffering from long- lasting paranoid schizophrenia - a case study
}

Uwarunkowania psychopatologiczne i następstwa somatyczne próby samobójczej poprzez zażycie środków żrących przez pacjentkę długotrwale chorującą na schizofrenię paranoidalną - analiza przypadku

\section{Małgorzata Romaniuk²ABCDEF https://orcid.org/0000-0001-8838-6291, Julita Poleszak-Szabat ${ }^{2}$ BEF, https://orcid.org/0000-0002-5166-6262, Paweł Krukow ${ }^{1}$ BCDE, https://orcid.org/0000-0001-9497-2713}

${ }^{1}$ Department of Clinical Neuropsychiatry, Medical University of Lublin, Poland ${ }^{2}$ Doctoral School of the Medical University of Lublin, Poland

\begin{abstract}
Background: Schizophrenia is a chronic mental illness that affects 20 million people worldwide. Patients diagnosed with paranoid schizophrenia are characterized by cognitive deficits and the so-called negative symptoms, which significantly lower their quality of life and have implications for their independence and ability to fulfill various social roles.

Aim: This study aims to present the case of a 49-year-old woman who has been suffering from schizophrenia for a long time and, due to a psychotic exacerbation with delusions and auditory hallucinations in the form of ordering voices, attempted suicide by ingesting a highly corrosive chemical agent used for unblocking pipes (the so-called "mole").

Case report: The patient was admitted to the 1st Department of Psychiatry, Psychotherapy and Early Intervention of SPSK 1 in Lublin for psychiatric treatment, after being transferred from the SPSK 1 Surgery Clinic, where she was initially admitted after the suicide attempt.

Discussion: The psychotic exacerbation in the patient could have resulted from sensory deprivation due to her feeling of loneliness and deep social isolation.
\end{abstract}

Keywords: schizophrenia, suicide, psychopathology

\section{Streszczenie}

Wstęp: Schizofrenia jest przewlekłą chorobą psychiczną dotykającą 20 milionów ludzi na całym świecie. U pacjentów z rozpoznaniem schizofrenii paranoidalnej wraz z długością trwania choroby nasilają się deficyty poznawcze oraz tzw. objawy negatywne, co istotnie obniża jakość życia i pociąga za sobą negatywne skutki w zakresie samodzielności i możliwości pełnienia różnych ról społecznych.

Cel: Celem pracy było przedstawienie przypadku 49-letniej kobiety długotrwale chorującej na schizofrenię, u której na tle zaostrzenia psychotycznego, przebiegającego z urojeniami i halucynacjami słuchowymi w postaci głosów nakazujących doszło do próby samobójczej dokonanej poprzez spożycie silnie żrącego środka chemicznego.

Opis przypadku: Pacjentka przyjęta do I Kliniki Psychiatrii, Psychoterapii i Wczesnej Interwencji SPSK 1 w Lublinie celem podjęcia leczenia psychiatrycznego, przeniesiona z Kliniki Chirurgii SPSK 1, gdzie pierwotnie trafiła po próbie samobójczej poprzez wypicie środka żrącego służącego do udrażniania rur (tzw. kret).

Dyskusja: Zaostrzenie psychotyczne u scharakteryzowanej przez nas pacjentki, mogło być następstwem deprywacji sensorycznej wynikającej z osamotnienia i głębokiej izolacji społecznej.

Słowa kluczowe: schizofrenia, samobójstwo, psychopatologia 


\section{Introduction}

Schizophrenia is a chronic mental illness that affects 20 million people worldwide [1]. Compared to the general population, people with this condition are 2-3 times more likely to suffer premature death [2]. It has been reported that the number of individuals who attempt suicide but do not succeed is about 10-15 times greater than the number of people who die as a result of suicide [3]. Recent studies have also shown that women are more likely to attempt suicide than men $[4,5]$.

In patients diagnosed with paranoid schizophrenia, symptoms such as impaired communication skills, difficulties in acquiring competences, and less satisfactory interpersonal relationships are observed, which significantly lower their quality of life and have implications for their independence and ability to perform various activities [6]. As a result of the increased burden associated with a long-term psychological problem, social isolation often worsens. This situation can be caused by the symptoms themselves but also through stigmatization by others, including relatives [7,8]. A potential consequence of social isolation, especially in a combination with a lack of social support, may be an increasing limitation of stimuli and information influx from outside, which is defined as sensory deprivation [9]. Short-term sensory deprivation can be a relaxing state; however, long-term exposure can lead to increased anxiety or even hallucinatory experiences. Such situation is particularly important for patients with long-term disease originated from endogenous psychosis, development or worsening the anxiety or the so-called productive psychopathology, along with hallucinations, delusions and disorganization [10].

Generally, in people diagnosed with schizophrenia, the factors that increase the risk of suicidal behavior include the presence of persecutory delusions, tendency of aggressive or impulsive behavior, previous suicide attempts, and the use of psychoactive substances [11]. Furthermore, studies have demonstrated that a majority of the patients with schizophrenia who commit suicide had productive symptoms (e.g. hallucinations), and prior to the attempt, experienced depressed mood, the severity of which often met the criteria of moderate and severe depressive episode [12]. In addition, nearly half of the patients with schizophrenia who attempted suicide had auditory hallucinations in the form of ordering voices, which, together with depressive symptoms, increase the risk of suicidal behavior [13].

\section{Objective}

In this paper, we present the case of a 49-year-old woman who has been suffering from schizophrenia for a long time and attempted suicide by ingesting a highly corrosive chemical agent during a psychotic exacerbation marked by delusions and auditory hallucinations in the form of commanding voices. We also discuss the somatic consequences of this suicide attempt, including damage to parts of the digestive and respiratory systems, which, along with the coexisting psychotic psychopathology, had a significant impact on the further psychiatric and somatic treatment.

\section{Case report}

Our case represents a 49-year-old female who had no children, had been trained as a farmer technician, and living alone for 2 years on a pension. Psychiatrically hospitalized seven times. During the long-term treatment, the patient was diagnosed with several types of psychiatric diseases including bipolar disorder and recurrent depressive disorders. She has been taking Risperidon $3 \mathrm{mg}$, Mianserin $10 \mathrm{mg}$, and Sodium Valproate $300 \mathrm{mg}$. Figure 1 presents the time course of the patient's subsequent hospitalizations and the treatment given.

The patient was admitted to the 1st Department of Psychiatry, Psychotherapy and Early Intervention of SPSK 1 in Lublin for psychiatric treatment, after being transferred from the Department of Surgery of SPSK 1 after a suicide attempt by drinking a corrosive agent used to unblock the pipes (the so-called "mole"). According to her account, she "felt fine" for six months and was in a stable mental state. The patient stated that her mental health deteriorated with the feeling of loneliness that intensified before Easter and that she experienced auditory hallucinations in the form of male voices, ordering her to commit suicide with the wording: "take a 'mole' and drink it."

The patient was initially inactive in the ward, spending most of her time in bed and in a depressed mood. She reported increased feelings of guilt and sin and also complained of prolonged sleep latency. Although the patient declaratively denied productive symptoms during her stay in the Department of Psychiatry, her behaviors suggested that she was experiencing auditory hallucinations. She also denied suicidal tendencies when speaking with doctors, but spontaneously revealed resignation and suicidal thoughts in some instances. After 2 weeks of hospitalization, the patient admitted that she felt guilty and "sinful" about the attempted suicide. She was completely unaware of the morbid motivation of the suicide attempt. In addition to the above symptoms, her clinical picture revealed negative symptomatology as well as formal and content-related thinking disorders.

At the end of the second week of hospitalization, the patient reported increased difficulties in consuming food and fluids and was therefore administered intravenous 
Table 1. Results of imaging and laboratory tests of the patient.

\begin{tabular}{|l|l|}
\hline $\begin{array}{l}\text { Abdominal } \\
\text { ultrasound }\end{array}$ & $\begin{array}{l}\text { A large number of reflections from bowel loops complicating complete evaluation; } \\
\text { enlarged liver, homogeneous, hyperechoic features of steatosis; areas of lower echo } \\
\text { corresponding to less fatty flesh at the gallbladder bed; extra- and intrahepatic bile } \\
\text { ducts not dilated; gallbladder invisible; pancreatic area not available for examination; } \\
\text { spleen not enlarged, homogeneous, normochogenic; kidneys are of typical size, with } \\
\text { normal corticospinal structure, and no signs of urinary stagnation or reflections } \\
\text { characteristic of textured deposits; a cyst with a left kidney septum, } 23 \text { mm in size; } \\
\text { urinary bladder with smooth wall outlines; homogeneous uterus; abdominal aorta, } \\
\text { perioral area visible fragmentarily, to the extent sufficient for examination without } \\
\text { visible pathological changes; no evidence of free abdominal fluid }\end{array}$ \\
\hline Chest X-ray & $\begin{array}{l}\text { Increased bronchial and peribronchial drawing of the lower lung fields, right capacity; } \\
\text { pulmonary fields with preserved aeration; vascular lung cavities, slightly thickened; } \\
\text { silhouette of the heart is not enlarged; diaphragm on tie contours, with the left dome } \\
\text { set high; a large gas bubble in the fundus projection }\end{array}$ \\
\hline Laboratory tests & $\begin{array}{l}\text { Glucose-125 mg/dl } \\
\text { gamma-glutamyltransferase-78 IU/l } \\
\text { Nt-proBNP-533 pg/ml } \\
\text { D-dimer-2038 ng/ml } \\
\text { CRP-292 mg/l } \\
\text { TSH-0.0043 } \\
\text { fT4-21.25 } \\
\text { fT3-3.38 }\end{array}$ \\
\hline
\end{tabular}

fluid therapy. A surgical consultation was performed, during which esophagoscopy was performed. After a few days, the patient was transferred to the General Surgery Clinic for further diagnosis and treatment as she complained of discomfort with oral feeding.

An esophagoscopy revealed a severe inflammatory reaction throughout the pharynx, epiglottis, and esophagus mucosa. The esophagus was not obstructed by the apparatus at a height of about $30 \mathrm{~cm}$. Therefore, a balloon expansion was performed, but transitions below were not achieved. The patient was transferred back to the Department of Psychiatry.

The results of imaging and laboratory tests carried out during psychiatric and surgical hospitalization are presented in Table 1. The findings were consulted with an internal diseases specialist who diagnosed that the patient had subclinical hyperthyroidism and tachycardia.

During hospitalization, Olanzapine $10 \mathrm{mg}$ and Mirtazapinum $30 \mathrm{mg}$ (per peg) were administered to the patient for gastrostomy. However, her mental state did not significantly improve after pharmacotherapy and other forms of therapeutic interactions. The level of criticism over the suicide attempt itself increased, while the underlying disease was not fully understood. Due to her psychological and somatic conditions, which included, inter alia, the inability to eat normally and constant risk of dehydration, the patient was referred to a Care and Treatment Institution.

\section{Discussion}

The described case of a patient diagnosed with schizophrenia, who attempted suicide under the influence of psychotic symptoms, illustrates the complications that can arise from both psychiatric interactions and treatment of the somatic consequences of the attempt. We believe that the psychotic exacerbation in the patient could have, at least partially, resulted from sensory deprivation due to her feeling of loneliness and deep social isolation.

In a person diagnosed with a mental illness, treatment of serious, physiological consequences of a suicide attempt encounters formal and legal difficulties. This is due to the fact that specialists other than psychiatrists may consider that such a person is fundamentally incapable of giving informed consent to perform certain medical procedures, including surgical interventions, which may prevent them from providing adequate medical care.

One of the greatest challenges of psychiatric treatment is the continuous development of community care organizations, the lack of which will significantly limit the provision of proper support to people with schizophrenia outside of hospital settings. The presented case demonstrates the potential consequences of the lack of community support in a long-term mentally ill people. An increased social isolation, which through many mechanisms, including interpersonal and sensory deprivation, may lead to the deterioration of mental health. Moreover, insufficient development of community 


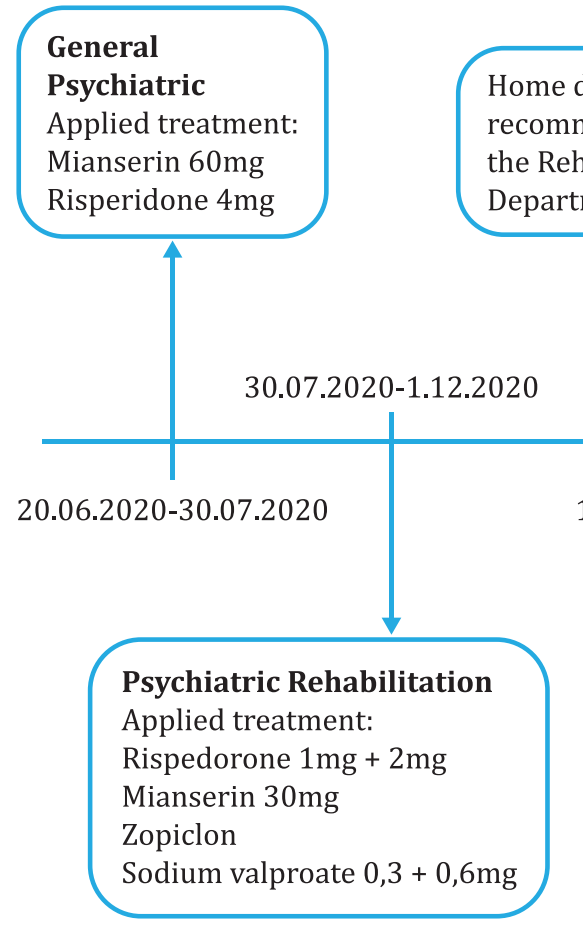

Home discharge with recommendations as in the Rehabilitation Department

\section{1st Department of Psychiatry Psychotherapy and Early Intervention}

Applied treatment:

Venlafaxinum $75 \mathrm{mg}$

Sodium valproate $0,5+0,5 \mathrm{mg}$

Trazodon $75 \mathrm{mg}$

Metoprolol

Sulpiride $50 \mathrm{mg}$

Mainserin $10 \mathrm{mg}$

Fig. 1. Time course of subsequent hospitalizations of the patient and the treatment applied.

Department of General Surgery, Gastroenterology and Neoplasms of the Digestive System

Conservative treatment was applied care also makes it impossible to effectively monitor the patient's mental state, including suicidal risk, as well as to continue somatic and psychiatric treatment, which would allow at least partial recovery after a suicide attempt.

\section{Conclusions}

To monitor suicidal risk in patients with paranoid schizophrenia, appropriate standards for dealing with a suicidal crisis should be proposed. There is a constant need for the development of community psychiatric care. Suicidal behaviors may have serious consequences for the somatic health of patients with long-term mental illness. Therefore, it is necessary to further develop the principles for organizing interdisciplinary medical care for this population.

\section{Wstęp}

Schizofrenia jest przewlekłą chorobą psychiczną dotykającą 20 milionów ludzi na całym świecie. [1] Osoby ze schizofrenią są 2-3 razy bardziej narażone na przedwczesną śmierć w porównaniu do jednostek $\mathrm{z}$ populacji ogólnej. [2] Liczba osób podejmujących próby samobójcze bez skutku śmiertelnego jest około 10-15 razy większa od liczby osób, które umierają w wyniku samobójstwa. [3] Ostatnie badania wykazały, że to kobiety częściej podejmują próby samobójcze. [4,5]

$\mathrm{U}$ pacjentów $\mathrm{z}$ rozpoznaniem schizofrenii paranoidalnej wraz $\mathrm{z}$ długością trwania choroby nasilają się deficyty poznawcze oraz tzw. objawy negatywne (m.in. bladość afektu, zanik inicjatywy, trudności w nawiązywaniu i podtrzymywaniu relacji interpersonalnych), co istotnie obniża jakość życia i pociąga za sobą negatywne skutki w zakresie samodzielności i możliwości pełnienia różnych ról społecznych. [6] W wyniku narastania obciążenia związanego z długotrwałą chorobą psychiczną, często dochodzi do pogłębiania się izolacji społecznej, zarówno w wyniku samych objawów, jak i stygmatyzacji ze strony innych, w tym osób bliskich pacjentom. [7,8] 
Potencjalną konsekwencją izolacji społecznej, szczególnie współwystępującej z brakiem wsparcia ze strony opieki środowiskowej, narastającymi deficytami poznawczymi może być pogłębiające się ograniczenie dopływu bodźców oraz informacji z zewnątrz działających na jeden lub kilka zmysłów, określane jako deprywacja sensoryczna. [9] Krótkotrwała deprywacja może być dla organizmu relaksująca, jednak długotrwała może prowadzić do podwyższenia niepokoju, a także, co szczególnie istotne dla pacjentów obciążonych długotrwałą chorobą z kręgu psychoz endogennych, rozwojem lub pogłębieniem się psychopatologii wytwórczej, wraz z halucynacjami, urojeniami oraz dezorganizacją. [10]

Generalnie, wśród czynników zwiększających ryzyko zachowań samobójczych u osób z rozpoznaniem schizofrenii wymienia się: obecność urojeń prześladowczych, skłonność do agresji lub impulsywne zachowanie, wcześniejsze próby samobójcze i stosowanie substancji psychoaktywnych. [11] Dodatkowo badania wykazują, że znaczny odsetek pacjentów z rozpoznaniem schizofrenii popełniających samobójstwo doświadczało objawów wytwórczych oraz przed podjęciem próby występowały u nich istotne obniżenia nastroju, nierzadko osiągające nasilenie spełniające kryteria umiarkowanego i ciężkiego epizodu depresji. [12] Co istotne, inni autorzy wskazują, że u blisko połowy osób z rozpoznaniem schizofrenii dokonujących prób samobójczych odnotowano halucynacje słuchowe $\mathrm{w}$ postaci głosów nakazujących, co dodatkowo, wraz symptomami depresyjnymi zwiększa ryzyko zachowań suicydalnych [13].

\section{Cel}

Celem pracy było przedstawienie przypadku 49-letniej kobiety długotrwale chorującej na schizofrenię, u której na tle zaostrzenia psychotycznego, przebiegającego z urojeniami i halucynacjami słuchowymi w postaci głosów nakazujących doszło do próby samobójczej dokonanej poprzez spożycie silnie żrącego środka chemicznego. Poza tym, chcemy przedstawić konsekwencje somatyczne tej próby samobójczej, związane z uszkodzeniem części układu pokarmowego i oddechowego, które, łącznie z współwystępującą psychopatologią psychotyczną istotnie wpłynęły na możliwości i komplikacje dalszego leczenia, zarówno psychiatrycznego, jak i somatycznego.

\section{Opis przypadku}

Pacjentka lat 49, panna, bezdzietna, zamieszkała samotnie, z wykształcenia - technik rolnik, od 2 lat na rencie. Dotychczas 7 razy hospitalizowana psychiatrycznie. W przebiegu długotrwałego leczenia rozpoznawano wiele jednostek chorobowych, między innymi: zaburzenia afektywne dwubiegunowe oraz zaburzenia depresyjne nawracające. Do tej pory przyjmowała: Rysperydon $3 \mathrm{mg} / \mathrm{d}$, Mianserynę $10 \mathrm{mg}$, Walproinian sodu $300 \mathrm{mg}$. Rycina 1 obrazuje przebieg czasowy kolejnych hospitalizacji pacjentki wraz $\mathrm{z}$ zastosowanym leczeniem.

Pacjentka została przyjęta do I Kliniki Psychiatrii, Psychoterapii i Wczesnej Interwencji SPSK $1 \mathrm{w}$ Lublinie celem podjęcia leczenia psychiatrycznego, przeniesiona $\mathrm{z}$ Kliniki Chirurgii SPSK 1, gdzie pierwotnie trafiła po próbie samobójczej poprzez wypicie środka żrącego służącego do udrażniania rur (tzw. kret). Według relacji pacjentki przez pół roku "czuła się dobrze" i była w stabilnym stanie psychicznym. Pogorszenie zdrowia psychicznego pacjentka wiązała z uczuciem samotności, które nasiliło się przed świętami Wielkanocy. Pacjentka relacjonowała iż w/w okresie doświadczała omamów słuchowych, które miały postać głosów męskich, nakazujących popełnienie samobójstwa o treści: „weź kreta i wypij”.

W czasie pobytu początkowo pacjentka nie podejmowała aktywności w Oddziale - większość czasu spędzała w łóżku, zaznaczał się wyraźnie obniżony nastrój. Pacjentka zgłaszała nasilone poczucie winy i grzechu oraz skarżyła się na wydłużenie latencji snu. Podczas pobytu w Klinice Psychiatrii pacjentka deklaratywnie zaprzeczała objawom wytwórczym, niemniej na poziomie behawioralnym ujawniała zachowania sugerujące doświadczanie halucynacji słuchowych poprzez nasłuchiwanie. Również deklaratywnie, w kontakcie z lekarzami zaprzeczała tendencjom samobójczym, jednak w niektórych sytuacjach spontanicznie ujawniała myśli rezygnacyjne i suicydalne. $W$ innych sytuacjach, po okresie około dwóch tygodni trwania hospitalizacji przyznawała, że ma poczucie winy i „grzeszności” związane z podjętą próbą samobójczą. Pacjentka nie miała wglądu w chorobową motywację podjętej próby samobójczej. Poza powyższymi objawami, obraz kliniczny zdominowany był także przez symptomatologię negatywną oraz formalne i treściowe zaburzenia myślenia.

Pod koniec drugiego tygodnia hospitalizacji pacjentka zgłaszała nasilone trudności w spożywaniu pokarmów i płynów - włączono płynoterapię dożylną. Przeprowadzono konsultację chirurgiczną, podczas której wykonano skopię przełyku. Po kilku dniach, z powodu braku możliwości doustnego żywienia pacjentki podjęto decyzję o jej przeniesieniu do Kliniki Chirurgii Ogólnej celem dalszej diagnostyki i leczenia.

Wykonano esophagoskopię, w której uwidoczniono błonę śluzową gardła, nagłośni i przełyku na całej długości z bardzo dużym odczynem zapalnym. Na wysokości około $30 \mathrm{~cm}$ zwężenie przełyku nieprzepuszczające aparatu. Wykonano rozszerzenie balonowe - przejścia poniżej jednak nie uzyskano. Przeniesiono pacjentkę ponownie do 
Tabela 1. Wyniki badań obrazowych i laboratoryjnych pacjentki.

\begin{tabular}{|l|l|}
\hline USG jamy brzusznej & $\begin{array}{l}\text { Duża ilość odbić z pętli jelit utrudnia pełną ocenę. Wątroba powiększona, jednorodna, } \\
\text { hiperechogeniczna - cechy stłuszczenia. Przy loży pęcherzyka źłciowego obszary } \\
\text { niższego echa odpowiadające mniej stłuszczonemu miąższowi. Drogi żółciowe } \\
\text { zewnątrz- i wewnątrzwątrobowe nieposzerzone. Pęcherzyk żółciowy niewidoczny. } \\
\text { Pole trzustki niedostępne badaniu. Śledziona niepowiększona, jednorodna, } \\
\text { normoechogeniczna. Obie nerki typowej wielkości, o prawidłowej strukturze } \\
\text { korowo-rdzeniowej, bez cech zastoju moczu, ani odbić charakterystycznych dla } \\
\text { upostaciowionych złogów. Torbiel z przegrodą lewej nerki wielkości 23mm. Pęcherz } \\
\text { moczowy o gładkich obrysach ścian. Macica jednorodna. Aorta brzuszna, okolica } \\
\text { okołoaortalna widoczne fragmentarycznie, w zakresie dostępnym badaniem bez } \\
\text { uchwytnych zmian patologicznych. Bez cech wolnego płynu wamie brzusznej. }\end{array}$ \\
\hline $\begin{array}{l}\text { RTG klatki } \\
\text { piersiowej }\end{array}$ & $\begin{array}{l}\text { Wzmożony rysunek oskrzelowy i około oskrzelowy dolnych pól płuc, szczególnie } \\
\text { prawego. Poza tym pola płucne o zachowanej powietrzności. Wnęki płuc naczyniowe, } \\
\text { prawa nieco zagęszczona. Sylwetka serca niepowiększona. Przepona o gładkich } \\
\text { obrysach. Jej lewa kopuła wysoko ustawiona. Duża bańka gazu w rzucie dna żołądka. }\end{array}$ \\
\hline $\begin{array}{l}\text { Badania } \\
\text { laboratoryjne }\end{array}$ & $\begin{array}{l}\text { Glukoza - } 125 \mathrm{mg} / \mathrm{dl} \\
\text { Gamma-glutamylotrasferaza (GGT) - 78 IU/l } \\
\text { Nt-proBNP- } 533 \text { pg/ml } \\
\text { D-DIMER- } 2038 \text { ng/ml } \\
\text { CRP- 292 mg/l } \\
\text { TSH - 0,0043 } \\
\text { fT4 - 21,25 } \\
\text { fT3 - 3,38 }\end{array}$ \\
\hline
\end{tabular}
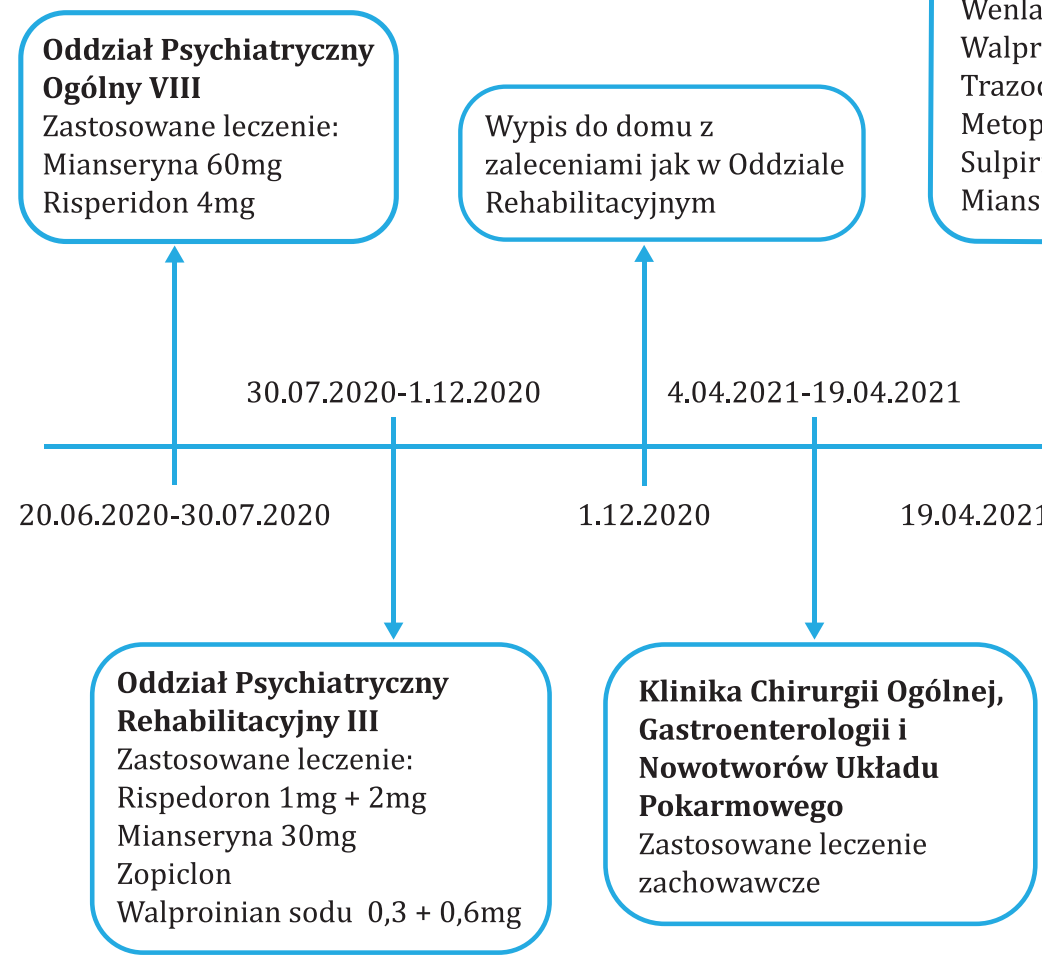

Ryc. 1. Przebieg czasowy kolejnych hospitalizacji pacjentki wraz z zastosowanym leczeniem.
I Klinika Psychiatrii, Psychoterapii i Wczesnej Interwencji

Zastosowane leczenie:

Wenlafaksyna $75 \mathrm{mg}$

Walproinian sodu $0,5+0,5 \mathrm{mg}$

Trazodon $75 \mathrm{mg}$

Metoprolol

Sulpiride 50mg

Mianseryna $10 \mathrm{mg}$

Klinika Chirurgii -

Esophagoskopia

Zastosowane leczenie:

Omeprazol 2x40mg

Diazepam $2 \times 10 \mathrm{mg}$

Olanzapina 2x10mg

Enoksaparyna 40mg

Meropenem 3x1g

Metronidazol 3x500mg

Worek żywieniowy 
Kliniki Psychiatrii.

W tabeli prezentujemy wyniki badań obrazowych i laboratoryjnych przeprowadzonych podczas hospitalizacji psychiatrycznej i chirurgicznej. Skonsultowano wyniki badań ze specjalistą chorób wewnętrznych, który rozpoznał subkliniczną nadczynność tarczycy oraz tachykardię u pacjentki.

Podczas hospitalizacji zaproponowano podawanie leku Olanzapiny $10 \mathrm{mg}$ oraz Mirtazapiny $30 \mathrm{mg}$ do gastrostomii (per peg).

Po zastosowanej farmakoterapii oraz innych formach oddziaływań terapeutycznych nie uzyskano jednak satysfakcjonującej poprawy stanu psychicznego. Poziom krytycyzmu odnośnie samej próby samobójczej zwiększył się, natomiast ogólnie nie uzyskano pełnego wglądu w chorobę podstawową. Z uwagi na stan psychiczny, ale także somatyczny pacjentki, związany między innymi z niepełną możliwością normalnego odżywania się, ciągłym ryzykiem odwodnienia podjęto decyzję o skierowaniu pacjentki do Zakładu Opiekuńczo-Leczniczego.

\section{Dyskusja}

Opisany przypadek pacjentki z rozpoznaniem schizofrenii, która dokonała próby samobójczej pod wpływem objawów psychotycznych, obrazuje komplikacje związane z oddziaływaniem zarówno psychiatrycznym, jak i leczeniem somatycznych konsekwencji podjętej próby. Uważamy, że przynajmniej częściowo, zaostrzenie psychotyczne u scharakteryzowanej przez nas pacjentki, mogło być następstwem deprywacji sensorycznej wynikającej z osamotnienia i głębokiej izolacji społecznej.

Leczenie poważnych, fizjologicznych konsekwencji próby samobójczej dokonanej przez osobę ze zdiagnozowaną chorobą psychiczną napotyka trudności formalno-prawne, ponieważ często lekarze innych specjalności, niż psychiatrzy mogą uznawać, że osoba taka jest z gruntu niezdolna do udzielenia świadomej zgody na wykonanie określonych procedur medycznych, w tym interwencji chirurgicznych, co dodatkowo może komplikować udzielenie adekwatnej pomocy medycznej.

Jednym $\mathrm{z}$ największych wyzwań psychiatrii jest stałe rozwijanie organizacji opieki środowiskowej, ponieważ jej brak znacznie ogranicza udzielanie odpowiedniego wsparcia osób ze schizofrenią poza warunkami szpitalnymi. Zaprezentowany przez nas przypadek obrazuje potencjalne konsekwencje braku opieki środowiskowej osoby długotrwale chorującej psychicznie, związanego $\mathrm{z}$ pogłębiającą się izolacją społeczną, która za pośrednictwem wielu mechanizmów może stać się tłem pogarszania stanu zdrowia psychicznego, między innymi w wyniku deprywacji interpersonalnej i sensorycznej. Niewystarczający poziom rozwoju opieki środowiskowej uniemożliwia także efektywne monitorowanie stanu psychicznego pacjentów, również w zakresie ryzyka suicydalnego, ale także, tak jak w opisanym przypadku, kontynuowania leczenia somatycznego i psychiatrycznego, które umożliwiło by przynajmniej częściowy powrót do zdrowia pacjenta po próbie samobójczej.

\section{Wnioski}

Zagrożenie samobójstwem w schizofrenii paranoidalnej wymaga wdrożenia standardu postępowania w kryzysie suicydalnym. Istnieje ciągła potrzeba rozwoju psychiatrii środowiskowej. Zachowania suicydalne występujące na tle długotrwałej choroby psychicznej mogą doprowadzać do poważnych konsekwencji w zakresie zdrowia somatycznego pacjentów, w związku z czym, niezbędny jest dalszy rozwój zasad organizacji interdyscyplinarnej opieki medycznej nad tymi pacjentami.

\section{Conflict of interest}

The authors has declared no conflict of interest.

\section{References:}

1. GBD 2017 Disease and Injury Incidence and Prevalence Collaborators. Global, regional, and national incidence, prevalence, and years lived with disability for 354 diseases and injuries for 195 countries and territories, 1990-2017: a systematic analysis for the Global Burden of Disease Study 2017. Lancet. 2018; 392(10159): 1789-1858. doi: 10.1016/S01406736(18)32279-7.

2. Laursen TM, Nordentoft M, Mortensen PB. Excess early mortality in schizophrenia. Annu Rev Clin Psychol. 2014;10:42548. doi: 10.1146/annurev-clinpsy-032813-153657. Epub 2013 Dec 2.

3. Wyatt RJ, Henter I, Leary MC, Taylor E. An economic evaluation of schizophrenia--1991. Soc Psychiatry Psychiatr Epidemiol. 1995;30(5):196-205. doi: 10.1007/BF00789054.

4. Schwartz RC, Cohen BN. Psychosocial correlates of suicidal intent among patients with schizophrenia. Compr Psychiatry. 2001;42 (2): 118-23. doi: 10.1053/comp.2001.21222.

5. Meder J, Sierosławska K. Czynniki ryzyka samobójstwa w schizofrenii. Post. Psych. Neurol. 2004; 13: 153-159.

6. Mosiołek A. Schizophrenia as a disease of cognitive functioning. 2015; 12, 3: 128-136.

7. Khalsa HM, Salvatore P, Hennen J et al.: Suicidal events and accidents in 216 first-episode bipolar I disorder patients: predictive factors. J Affect Disord 2008; 106: 179-184.

8. Mann JJ: Neurobiology of suicidal behaviour. Nat Rev Neurosci 2003; 4: 819-828.

9. Hawkley LC, Cacioppo JT. Loneliness matters: a theoretical and empirical review of consequences and mechanisms. Ann Behav Med. 2010; 40(2): 218-27. doi: 10.1007/s12160-010-9210-8.

10. Grzywniak, C. Incorrect sensory integration as the constituent of mental disorders occurring both in the case of children and of young people and adult individuals alike. 2016; 13: 143-148.

11. Grzywa A, Kucmin A, Kucmin T. Samobójstwa - epidemiologia, czynniki, motywy i zapobieganie. Część I. Pol. Merk. Lek. 2009; 27 (161): 432-436.

12. Heilä H, Isometsä ET, Henriksson MM, Heikkinen ME, Marttunen 
MJ, Lönnqvist JK. Suicide and schizophrenia: a nationwide psychological autopsy study on age- and sex-specific clinical characteristics of 92 suicide victims with schizophrenia. Am J Psychiatry. 1997 Sep;154(9):1235-42. doi: 10.1176/ ajp.154.9.1235.

13. Harkavy-Friedman JM, Kimhy D, Nelson EA, Venarde DF, Malaspina D, Mann JJ. Suicide attempts in schizophrenia: the role of command auditory hallucinations for suicide. J Clin Psychiatry. 2003;64(8): 871-4.

\section{Corresponding author}

Małgorzata Romaniuk

Department of Clinical Neuropsychiatry,

Medical University of Lublin

goszarom@gmail.com

Otrzymano: 17.08 .2021

Zrecenzowano: 02.09.2021

Przyjęto do druku: 13.09.2021 